\title{
Comments and Discussion
}

With this issue, we institute a new section of the Journal entitled Comments and Discussion. There are many issues in physiological psychology that require debate or stimulate controversy. We encourage readers to submit letters, comments, brief articles, etc., concerning issues of importance, disagreements they may have with interpretations in papers published in the Journal, etc. All such communications will be reviewed before publication.

Dr. John F. Disterhoft in the following article deals with the search for the "engram," one of the most fascinating and perplexing problems in physiological psychology. A significant part of this fascination lies in the many and complex conceptual issues involved. Gabriel addressed one of these issues in this Journal last year. In the present paper, Disterhoft gives a somewhat different view of the same issue.

Richard F. Thompson 